\title{
USE OF AN INDIVIDUAL UNSATURATED LECITHIN FROM YEAST IN ANTIGENS FOR THE SERO-DIAGNOSIS OF SYPHILIS* \\ BY
}

\author{
DAVID B. TONKS AND ROVELLE H. ALLEN, with the technical assistance of \\ EVELYN FOWLER
}

\section{From the Laboratory of Hygiene, Department of National Health and Welfare, Ottawa, Canada}

Hanahan and Jayko (1952) isolated a pure individual unsaturated lecithin, L- $\alpha$-(dipalmitoleyl)lecithin, from fresh baker's yeast by adsorption on alumina. They showed that hydrogenation of this material produced the corresponding saturated lecithin which was identical with the synthetic L- $\alpha$-(dipalmitoyl)-lecithin of Baer and Maurukas (1952). The latter compound, when used in combination with cardiolipin and cholesterol, has given antigens suitable for the sero-diagnosis of syphilis (Tonks and Allen, 1953).

Samples of Hanahan's lecithins were obtained and tested in antigens prepared for the Kolmer complement-fixation test and the VDRL microflocculation test. Antigens containing the unsaturated lecithin proved to be reactive in both tests. Since this pure material is quite stable, as determined by chemical tests, is relatively easy to prepare, and is a solid which can be measured by weighing, it offers promise for use as the lecithin component of cardiolipin antigens.

Antigens containing the saturated material showed very little reactivity in the VDRL test when used at a concentration found previously by Tonks and Allen (1953) to be optimal for Baer's synthetic saturated lecithins. However, in the Kolmer test, Hanahan's preparation gave results almost identical to those obtained with Baer's material.

\section{Methou of Study}

The lecithins were carefully weighed and dissolved in absolute alcohol to give solutions containing $15 \mathrm{mg}$. lecithin per ml. alcohol. Antigens of various compositions were prepared volumetrically from these solutions and from alcohol solutions of cardiolipin and cholesterol. The cardiolipin was obtained commercially (Sylvana) and had been approved for use in antigens. The cholesterol solution contained 1.5 per cent. pure Pfanstiehl cholesterol (precipitated from alcohol for the Kline test). The lecithin solutions were stored in the dark at room temperature.

\footnotetext{
* Received for publication February 4, 1955.
}

VDRL Microflocculation Test.-Antigens were prepared containing 0.02 per cent. or 0.03 per cent. cardiolipin, varying amounts of unsaturated lecithin, and 0.9 per cent. cholesterol. One antigen was prepared with the saturated lecithin $(0.30$ per cent. $), 0.03$ per cent. cardiolipin, and 0.9 per cent. cholesterol. This was the composition found to be most satisfactory when using Baer's synthetic saturated lecithin. The various preparations were compared with standard VDRL antigen containing 0.03 per cent. cardiolipin, 0.2325 per cent. Pangborn lecithin, and 0.9 per cent. cholesterol. The latter antigen was run as a control in all tests.

In order to determine whether different batches of lecithin would give similar results, further samples were obtained from Dr. Hanahan. In all, three different preparations of each lecithin were tested.

The stability of antigen suspensions prepared from one mixture $(0.02$ per cent. cardiolipin, 0.475 per cent. unsaturated lecithin, and 0.9 per cent. cholesterol) was tested over a 24-hr period. Serum specimens were tested at $0,0 \cdot 5,3,6$, and 24 hrs (Table II, opposite). Each serum had been divided into several portions and a different portion was tested each time after inactivation at $56^{\circ} \mathrm{C}$. The antigen suspensions were kept at room temperature in the glass-stoppered bottles in which they were prepared.

An antigen mixture (No.8, Table I, opposite) was stored in the dark at room temperature in a screw-capped bottle for 18 months, and its reactivity was compared with that of standard VDRL antigen at regular intervals. In addition, an alcohol stock solution of the unsaturated lecithin was tested for stability at room temperature by preparing from it several different batches of the same antigen over a period of 18 months and comparing them serologically. Sufficient material, however, was not available to test the stability of the unsaturated lecithin in its pure solid form.

Kolmer Complement-Fixation Test.-Antigens were prepared containing $\mathbf{0 . 0 1 7 5}$ per cent. cardiolipin, varying amounts of unsaturated lecithin, and 0.3 per cent. cholesterol. One antigen was made with the saturated lecithin (0.1225 per cent.), 0.0175 per cent. cardiolipin, and 0.3 per cent. cholesterol ; this composition had been found previously to give the best results with Baer's saturated synthetic lecithin. Comparisons were made 
TABLE I

VDRL TEST. COMPARISON OF ANTIGENS, CONTAINING HANAHAN'S UNSATURATED L- $\alpha$-(DIPALMITOLEYL)LECITHIN, WITH STANDARD ANTIGEN

\begin{tabular}{|c|c|c|c|c|c|c|}
\hline \multirow{2}{*}{$\begin{array}{l}\text { Antigen } \\
\text { No. }\end{array}$} & \multicolumn{3}{|c|}{$\begin{array}{l}\text { Composition } \\
(\mathrm{g} . / 100 \mathrm{ml} .)\end{array}$} & \multirow{2}{*}{\begin{tabular}{|} 
Ratio \\
of \\
Cardio- \\
lipin \\
to \\
Lecithin
\end{tabular}} & \multicolumn{2}{|c|}{$\begin{array}{l}\text { Comparison with } \\
\text { Standard Antigen }\end{array}$} \\
\hline & $\begin{array}{c}\text { Cardio- } \\
\text { lipin }\end{array}$ & Lecithin & $\begin{array}{c}\text { Choles- } \\
\text { terol }\end{array}$ & & $\begin{array}{l}\text { Positive } \\
\text { Sera }\end{array}$ & $\begin{array}{l}\text { Negative } \\
\text { Sera }\end{array}$ \\
\hline 3 & 0.03 & 0.15 & 0.9 & $1: 5$ & $\begin{array}{c}\text { Much } \\
\text { weaker }\end{array}$ & Same \\
\hline 1 & 0.03 & $0 \cdot 30$ & 0.9 & $1: 10$ & Weaker & Same \\
\hline 4 & 0.03 & 0.45 & 0.9 & $1: 15$ & Weaker & Same \\
\hline 5 & 0.03 & 0.525 & 0.9 & $1: 17 \cdot 5$ & Weaker & Same \\
\hline 8 & $0.02^{*}$ & 0.40 & 0.9 & $1: 20$ & $\begin{array}{l}\text { Slightly } \\
\text { weaker }\end{array}$ & Same \\
\hline 14 & 0.02 & 0.45 & 0.9 & $1: 22 \cdot 5$ & $\begin{array}{l}\text { Slightly } \\
\text { weaker }\end{array}$ & Same \\
\hline 15 & 0.02 & 0.475 & 0.9 & $1: 23 \cdot 25$ & $\begin{array}{c}\text { Very } \\
\text { slightly } \\
\text { weaker }\end{array}$ & Same \\
\hline 9 & 0.02 & 0.50 & 0.9 & $1: 25$ & $\begin{array}{c}\text { Very } \\
\text { slightly } \\
\text { stronger }\end{array}$ & $\begin{array}{l}\text { Some- } \\
\text { times } \\
\text { slightly } \\
\text { rough }\end{array}$ \\
\hline
\end{tabular}

* The percentage of cardiolipin was lowered to 0.02 per cent. so that antigens of higher ratios than $1: 17 \cdot 5$ could be prepared.

with standard Kolmer cardiolipin antigen containing 0.0175 per cent. cardiolipin, 0.2 per cent. Pangborn lecithin, and $\mathbf{0 . 3}$ per cent. cholesterol (Allen and Mason, 1952). Antigen dilutions of $1: 300$ were found to be optimal for most preparations.

To evaluate the various antigens (both Kolmer and VDRL), tests were performed upon individual sera and several dilutions of pooled positive sera which gave negative, weakly positive, or positive reactions with the standard cardiolipin antigens. Some idea of the specificity was obtained by testing a small number of sera which had previously been examined with a battery of tests and found to be negative.

\section{EXPERIMENTAL RESULTS}

\section{(A) With Unsaturated L- $\alpha$-(Dipalmitoleyl)-Lecithin}

(1) VDRL Test.-The results obtained with antigens containing the unsaturated lecithin, compared with standard VDRL antigen, are summarized in Table I.

Fine particles were obtained consistently with all antigens except No. 9 when the antigen suspensions were prepared, and when these were mixed with negative sera as prescribed for the test. Antigen No. 9 showed at times a slight tendency to roughness, but not enough to reject it for this reason. All other antigens gave negative pictures very similar to those produced with the standard antigen. With positive sera, typical clumping occurred. Antigen No. 15 (0.02 per cent. cardiolipin, 0.475 per cent. unsaturated lecithin, and 0.9 per cent. cholesterol)
TABLE II

VDRL TEST. STABILITY OF ANTIGEN SUSPENSION (IN DUPLICATE) CONTAINING UNSATURATED LECITHIN

\begin{tabular}{|c|c|c|c|c|c|c|c|c|c|c|}
\hline \multirow{3}{*}{$\frac{\begin{array}{c}\text { Serum } \\
\text { No. }\end{array}}{1}$} & \multicolumn{10}{|c|}{ Readings* at } \\
\hline & \multicolumn{2}{|c|}{$0 \mathrm{hr}$} & \multicolumn{2}{|c|}{$\frac{1}{2} \mathrm{hr}$} & \multicolumn{2}{|c|}{3 hrs } & \multicolumn{2}{|c|}{$6 \mathrm{hrs}$} & \multicolumn{2}{|c|}{$24 \mathrm{hrs}$} \\
\hline & 3 & 3 & $3-$ & 3 & 3 & 3 & 3 & 3 & 3 & 3 \\
\hline 2 & SR & SR & SR & SR & $\mathbf{R}$ & $\mathbf{R}$ & $\mathbf{R}$ & $\mathbf{R}$ & SR & SR \\
\hline 3 & 4 & 4 & 4 & 4 & 4 & 4 & 4 & 4 & 4 & 4 \\
\hline 4 & $3+$ & $4-$ & $3+$ & $3+$ & $4-$ & $4-$ & $4-$ & 4 & 3 & $3+$ \\
\hline 5 & - & - & - & - & - & - & 一 & 一 & - & - \\
\hline 6 & 1 & 1 & 1 & $1-$ & $1+$ & $1+$ & 1 & $1+$ & $1-$ & 1 \\
\hline
\end{tabular}

${ }^{*} \mathbf{R}=$ rough negative ; $\mathbf{S R}=$ slightly rough. The plus and minus signs indicate slight differences in particle size. It is recognized that the authors of the VDRL test recommend that only the terms "positive", "weakly positive", and " negative" should be used "positive", "weakly positive", and "negative" should be used often advantageous to use numerical readings.

was selected as the most consistently satisfactory, although Antigen No. 9 also was very similar in behaviour to the standard antigen and sometimes agreed more closely. No positive reactions were obtained when 35 sera, which had been previously checked with a battery of serological tests and found to be negative, were tested with Antigen No. 15.

Table II gives the results obtained in the antigen suspension stability studies which were carried out in duplicate. All readings were made by one experienced operator. It can be seen that the antigen suspensions retained the same reactivity for at least $24 \mathrm{hrs}$. Heating a suspension at $56^{\circ} \mathrm{C}$. for $5 \mathrm{~min}$. immediately after preparation was found to have little effect. This is different from the rather large increases in sensitivity found when suspensions prepared from synthetic saturated lecithin antigens were heated in a like fashion (Tonks and Allen, 1953).

No change in reactivity could be detected in the antigen (No. 8) which was stored at room temperature in the dark for 18 months (Table III). Although

TABLE III

ANTIGEN STABILITY STUDY (VDRL TEST-UNSATURATED LECITHIN). RESULTS WITH THE SAME PREPARATION OF ANTIGEN NO. 8 COMPARED WITH STANDARD VDRL ANTIGEN AT TWO DIFFERENT TIMES 18 MONTHS APART

\begin{tabular}{|c|c|c|}
\hline Description & $\begin{array}{l}\text { May, } \\
1953\end{array}$ & $\begin{array}{c}\text { October, } \\
1954\end{array}$ \\
\hline $\begin{array}{l}\text { Number of specimens giving stronger } \\
\text { reactions with Antigen No. } 8\end{array}$ & $12^{*}$ & 12 \\
\hline Number giving same reaction & 43 & 43 \\
\hline $\begin{array}{l}\text { Number giving weaker reactions with } \\
\text { Antigen No. } 8\end{array}$ & 11 & 7 \\
\hline
\end{tabular}

* With the same serum, the difference between readings for the two antigens was never greater than 1+. In May, 1953, there were 22 negative, seventeen weakly positive, and 27 positive (fourteen $4+$ ) negative, seventeen weakly positive, and 27 positive (fourteen $4+$ ) sera : in October, 1954, fourteen negative, eleven weakly positive,
37 positive (twenty-two $4+$ ). This antigen was prepared in the initial 37 positive (twenty-two $4+$ ). This antigen was prepared in the initial
stages of the study which may account for the slight discrepancy in relative sensitivity as seen in this Table and in Table $I$. 
the complete antigen was thus proved to be stable, the alcohol solution of the unsaturated lecithin gave indications of slight changes when stored under similar conditions. Sufficient solid material was not available to prove this conclusively by carefully controlled experiments. It is recommended, however, that the alcohol solutions of the pure lecithins be stored in the cold.

Three preparations of Antigen No. 9, each containing a different lot of the lecithin, showed slight differences in reactivity; however, this may have been due to changes occurring in the alcohol stock solutions, since these were of different ages. The results were close enough to indicate that the three batches of lecithin were not grossly different in purity and composition.

(2) Kolmer Test.-The results obtained with antigens containing the unsaturated lecithin, compared with standard Kolmer antigen, are summarized in Table IV. Titres of $1: 300$ were used throughout.

TABLE IV

KOLMER TEST. ANTIGENS CONTAINING HANAHAN'S UNSATURATED LECITHIN COMPARED WITH STANDARD KOLMER ANTIGEN

\begin{tabular}{|c|c|c|c|c|c|}
\hline \multirow{2}{*}{$\begin{array}{c}\text { Anti- } \\
\text { gen } \\
\text { No. }\end{array}$} & \multicolumn{3}{|c|}{ Composition (g. $/ 100 \mathrm{ml}$.) } & \multirow{2}{*}{$\begin{array}{l}\text { Ratio of } \\
\text { Cardio- } \\
\text { lipin to } \\
\text { Lecithin }\end{array}$} & \multirow{2}{*}{$\begin{array}{l}\text { Reaction with } \\
\text { Positive Sera } \\
\text { compared with } \\
\text { Standard Antigen }\end{array}$} \\
\hline & $\begin{array}{c}\text { Cardio- } \\
\text { lipin }\end{array}$ & Lecithin & $\begin{array}{c}\text { Choles- } \\
\text { terol }\end{array}$ & & \\
\hline 12 & 0.0175 & $0 \cdot 245$ & $0 \cdot 3$ & $1: 14$ & Stronger \\
\hline 13 & 0.0175 & $0 \cdot 250$ & $0 \cdot 3$ & $1: 14 \cdot 3$ & Slightly stronger \\
\hline 19 & 0.0175 & $0 \cdot 256$ & $0 \cdot 3$ & $1: 14 \cdot 6$ & Same \\
\hline 16 & 0.0175 & 0.262 & $0 \cdot 3$ & $1: 15$ & Slightly weaker \\
\hline
\end{tabular}

Antigen No. 19 (0.0175 per cent. cardiolipin, 0.256 per cent. unsaturated lecithin, and 0.3 per cent. cholesterol) gave results that were close to those obtained with the standard Kolmer antigen. It was found, however, that antigens differing only in containing different batches of the lecithin gave slightly different results. This may have been due to changes in the stock alcohol solutions of the lecithin, as found in VDRL test experiments.

No positive reactions occurred with any of 48 negative sera which were tested with Antigen No. 16.

\section{(B) With Saturated L- $\alpha$-(Dipalmitoyl)-Lecithin}

(1) VDRL Test.-The saturated lecithin proved to be relatively inactive. Only with very strongly positive serum did the antigen containing 0.03 per cent. cardiolipin, 0.30 per cent. saturated lecithin, and 0.9 per cent. cholesterol show any signs of clumping. With negative serum the particles formed were larger than usual and crystalline in appearance. All three batches of the lecithin gave these results.
Since Baer's pure synthetic L- $\alpha$-(dipalmitoyl)-lecithin used in the same concentration gave a satisfactory antigen, it is concluded that the material produced by hydrogenation of the unsaturated lecithin contained an impurity in traces which affected its use in antigens for the VDRL test.

(2) Kolmer Test.-The antigen containing 0.0175 per cent. cardiolipin, $0 \cdot 1225$ per cent. lecithin, and 0.3 per cent. cholesterol gave results which were very similar to those obtained with an antigen of the same composition but containing Baer's synthetic $L-\alpha$-(dimyristoyl)-lecithin, and with standard Kolmer antigen. Baer's synthetic L- $\alpha$-(dimyristoyl)lecithin had been found previously to behave similarly to his synthetic L- $\alpha$-(dipalmitoyl)-lecithin. It is apparent, therefore, that the unknown factor which decreased the sensitivity in the VDRL test, had little, if any, effect in the Kolmer test.

Different batches of the saturated lecithin prepared by Hanahan gave antigens of about the same reactivity.

\section{Discussion}

At present lecithin extracted from beef heart or egg yolk and purified by the methods of Pangborn and others (1951) is being used in cardiolipin antigens. The method of purification is somewhat tedious and the end-product is actually a mixture of chiefly unsaturated lecithins. The composition varies with the source and it is difficult to produce material of standard sensitivity. This lecithin is also unstable in the solid form and is, therefore, preserved in alcohol solution, usually at refrigeration temperatures.

The method described by Hanahan gives an individual, chemically pure, unsaturated lecithin. The method of production is relatively simple and the starting material, fresh baker's yeast, is easily obtained. Whether material of the same purity, as tested by the serological methods described above, can be obtained from different batches of yeast, remains to be ascertained. It has been shown by Hanahan that his preparations are the same chemically as determined by $x$-ray diffraction, infra-red spectrophotometry, and other physical and chemical measurements. Traces of materials not detectable by these methods might affect antigenantibody reactions, however, and this could be a reason for the slight differences in results obtained with different batches of the lecithins, and also for the inactivity of the saturated lecithin in the VDRL test.

Hanahan and Jayko (1952) state that the unsaturated lecithin is quite stable to atmospheric oxidation. It is currently believed that oxidation of 
such compounds is catalysed by traces of metals such as copper and iron, and it is possible that these are absent in the chromatographed material of Hanahan and Jayko. We have found that the unsaturated lecithin is stable for at least $\mathbf{1 8}$ months in alcohol solution with cardiolipin and cholesterol, and that antigen suspensions containing it are stable for at least $24 \mathrm{hrs}$.

It is an interesting fact that more of the pure unsaturated lecithin than of Pangborn's lecithin (per unit weight of cardiolipin) is required to produce a VDRL antigen of standard sensitivity.

To our knowledge, this is the first time that an individual, completely unsaturated lecithin has been used in antigens for the sero-diagnosis of syphilis. On the basis of our work, we conclude that the unsaturated lecithin, if sufficiently reproducible from batch to batch, could be used as the lecithin component in cardiolipin antigens.

\section{SUMmary}

(1) A pure unsaturated individual lecithin, L- $\alpha$ (dipalmitoleyl)-lecithin, was tested as a component in cardiolipin antigens for the VDRL microflocculation test and the Kolmer complement-fixation test for syphilis and gave promising results.

(2) A pure saturated lecithin, L- $\alpha$-(dipalmitoyl)lecithin, prepared from the unsaturated form above by hydrogenation, was also tested. Antigens containing it were successfully used in the Kolmer test but showed little or no reactivity in the VDRL test.

\section{REFERENCES}

Allen, R. H., and Mason, M. A. (1952). Canad. J. publ. Hlth, 43, 128. Baer, E., and Maurukas, J. (1952). J. Amer. chem. Soc., 74, 158.

Hanahan, D. J., and Jayko, M. E. (1952). Ibid., 74, 5070.

Pangborn, M. C., Maltaner, F., Tompkins, V. N., Beecher, T., Thompson, W. R., and Flynn, M. R. (1951). "Cardiolipin Antigens ", p. 9. World Health Organization, Monograph Series No. 6. Geneva.

Tonks, D. B., and Allen, R. H. (1953). Science, 118, 35. 